\title{
What's new about multiple sclerosis and pregnancy?
}

\author{
Ana Turcu DUMINICA ${ }^{1}$, Nicolae GICA ${ }^{1}$, Radu BOTEZATU ${ }^{1,2}$, Anca Marina CIOBANU ${ }^{1,2}$, \\ Brindusa Ana CIMPOCA ${ }^{1}$, Corina GICA ${ }^{1}$, Gheorghe PELTECU ${ }^{1,2}$, Anca Maria PANAITESCU ${ }^{1,2}$ \\ ${ }^{1}$ Filantropia Clinical Hospital, Bucharest, Romania \\ 2 "Carol Davila" University of Medicine and Pharmacy, Bucharest, Romania
}

\begin{abstract}
Nowadays, women diagnosed with multiple sclerosis and belonging to the reproductive age group have high pregnancy rates, thus increasing the need of a careful pregnancy management in order to avoid maternal and fetal complications. The challenge of the chosen subject consists in identifying the available treatment that can be used during pregnancy time, emphasizing the need of a rigorous care during the preconceptional and postpartum period. The aim of the current review is to describe the management of a pregnant woman diagnosed with multiple sclerosis, in regards of treatment, anesthesia, mode of delivery and management and prevention of relapses during the postpartum period.
\end{abstract}

Keywords: pregnancy, multiple sclerosis, relapses, breastfeeding, puerperium

\section{INTRODUCTION}

More than twenty years have passed by since Confavreux et al. introduced into the world the reference study on multiple sclerosis in pregnancy, studying 254 pregnant females diagnosed with multiple sclerosis during 269 pregnancies, in over 12 European countries, establishing the rate of relapse per trimester and correlating it with the rate during the year before the pregnancy and concluding that the rate of relapse diminishes during parturiency, notably during the last trimester and enhances in the puerperium period, before restoring to the pre-pregnancy rate [1]. Described as one of the most frequent neurological diseases, multiple sclerosis is an autoimmune disorder that affects the central nervous system with neurological, physical and cognitive consequences [2]. The downfall of the myelin sheath leads to focal T-lymphocytic and macrophage infiltrations and oligodendrocyte demise, resulting in multifocal zones of inflammation with the final destination of central nervous system plaques, altering the transmission of nerve impulses, leading to cognitive, visual, autonomic and sensorimotor impairment, among others [2].
There are several types of multiple sclerosis (MS), each type influencing prognosis and treatment choice. Relapsing remitting MS (RRMS) is the prevailing type with acute attacks and remission periods; primary progressive MS (PPMS) is the type described to affect the spinal cord nerves; secondary progressive MS (SPMS) is a gradual phase of the primary multiple sclerosis; progressive relapsing MS (PRMS) ia described as a rare type with sexual, intestinal and urinary connotations [3]. Multiple sclerosis affects women 2.5 times more frequent than men, thus pregnancy or menopause implying important changes to the evolution of the disease, multiple sclerosis frequently being detected between 20 and 40 years [4,5].

\section{PATHOGENESIS, ENVIRONMENTAL AND GENETIC FACTORS DETERMINING MULTIPLE SCLEROSIS}

The pathogenesis of multiple sclerosis originates in the focal immune cell and cytokine infiltration that leads to inflammation of the white and gray matter tis- 
sues, the evolution of the disease being determined by the synergy between antigen presenting cells (APCs) with $T$ lymphocytes that trigger T helper (Th) cell (CD4+ T cells) mediation and adaptive immune feedback [6]. Toll-like receptors on APCs are stimulated by pathogen-associated molecules, resulting in the release of interleukin (IL)-12, IL-23 and IL-4, CD4+ T cell differentiation into Th1, Th2 or Th17, further releasing interferon gamma (IFN $)$ ) or type II interferon and tumor necrosis factor alpha (TNF- $\alpha$ ) that promote inflammation [7].

There are several environmental factors that are correlated with multiple sclerosis, as they are shown in Table 1 [8]. Tobacco use acts as a determining factor in the onset of multiple sclerosis through the release of nitric oxide (NO) and carbon monoxide (CO) with potential impairment to the neurons and oligodendrocytes, leading to apoptosis, axonal degeneration, and demyelination $[9,10,11]$. Regarding the vitamin deficiency, the lack of vitamin $D$ promotes the onset of multiple sclerosis, being correlated with gene expression and immune control, activating B lymphocyte apoptosis, IL-10 synthesis and IFN- $\gamma$ and IL-2 suppression [12-16], while vitamin B12 deficiency is involved in the damage of myelin shell components [17]. Moreover, in a paper published in 2011 by Sloka et al., in which data was collected from 54 studies, ultraviolet exposure was an important environmental factor to the prospect of promoting multiple sclerosis onset [18]. A Canadian collaborative study group on the genetic basis for familial aggregation in multiple sclerosis indicated that familial aggregation of multiple sclerosis is genetically determined [19]. Genes like HLA-C554 and HLA-DRB1*11 are noted to carry protective effects [20].

TABLE 1. Environmental factors correlated with multiple sclerosis [8]

\begin{tabular}{|l|}
\hline Viral infection \\
- Epstein-Barr virus (EBV) \\
- Human herpes virus type 6 (HHV 6) \\
\hline Mycoplasma pneumoniae \\
\hline Tobacco use \\
\hline Inappropriate diet, including vitamin deficiency \\
\hline UV exposure \\
\hline
\end{tabular}

\section{MULTIPLE SCLEROSIS AND PREGNANCY}

In the past years, pregnant women diagnosed with multiple sclerosis have been the subject of numerous scientific papers, assessing the effect of pregnancy on the evolution of the disease. Dahl et al., using Norwegian multiple sclerosis Registry and the Medical Birth Registry of Norway between 1967 and 2002, studied the correlation between maternal multiple sclerosis and pregnancy outcome [21]. The study concluded that neonates from mothers diagnosed with a manifest form of multiple sclerosis had a lower birth weight, possible from substandard intrauterine climate derived from the disease-induced altered immune state or as a cause of delivery via an elective caesarean section that usually was planned before full term [21]. Contrary to these results, the van der Kop study noted that multiple sclerosis was not considerably correlated with assisted vaginal delivery (odds ratio [OR], 0.78; 95\% confidence interval $[\mathrm{Cl}], 0.50-1.16 ; \mathrm{p}=0.20$ ) or cesarean section (OR, 0.94; 95\% Cl, 0.69-1.28; $p=0.69$ ) [22]. Assessing post-partum relapses and disability in multiple sclerosis women through an Italian prospective study, Pasto et al. showed no equivalence between postpartum relapses and disability and caesarean delivery [23]. In terms of MRI exposure during pregnancy and its potential fetal consequences, Ray et al., using Ontario databases that included births between 2003 and 2015 , concluded that using MRI during early pregnancy, in comparison to lack of exposure, did not augment the risk of adverse outcome to the fetus or during the first years after birth [24]. On the other hand, gadolinium MRI during pregnancy augmented the risk of rheumatological, inflammatory or infiltrative skin adverse outcomes, besides stillbirth or neonatal death, rare adverse outcomes being hard to be identified [24]. According to Paavilainen, with the help of MRI, it was shown that disease activity is decreased in late pregnancy and post-partum activation is a premature and frequent event in pregnant women diagnosed with multiple sclerosis [25].

\section{ANALGESIA AND BREASTFEEDING IN WOMEN WITH MULTIPLE SCLEROSIS}

The clinical implications of pregnant women diagnosed with multiple sclerosis continue to raise awareness among healthcare providers, particularly regarding the use of local regional analgesia that could induce further toxicity in the demyelinated area. The opinions of UK consultants obstetric anesthetists were assessed throughout a national survey, out of the 592 replies, $91 \%$ of respondents having seen fewer than 10 cases of multiple sclerosis in the past 10 years, the regional block being the first choice of analgesia in $79 \%$ of the cases, epidural in $4 \%$ of the cases of elective cesarean delivery, general anesthesia in $2 \%$ of cases of elective cesarean delivery and $3 \%$ in emergency cesarean delivery, regional blocks having the potential to lead to negative consequences such as prolonged block, leg weakness, bladder dysfunction and postnatal relapse of the disease [26]. On the other hand, focusing on women who experienced multiple sclerosis relapses during pregnancy, Lavie et al. analyzed the repercussion of neuraxial analgesia on the risk of relapse during early post-partum period, concluding that $24 \%$ experienced 
a relapse during pregnancy and $25 \%$ in the 3 months post-partum, no association being noted between neuraxial analgesia and post-partum relapse $(O R=1.08$, $p=0.78)$ [27].

In 2009, Langer-Gould released the axiom that exclusive breastfeeding has a protective role against postpartum relapses of multiple sclerosis, $36 \%$ of the women diagnosed with multiple sclerosis who breastfed exclusively for at least 2 months postpartum experienced relapses of the disease, while complementary suppression of menses seemed to contribute to this positive result [28]. In addition, a 2019 cross-sectional survey on 501 women concluded that breastfeeding did not substantially modify the risk of clinically definite multiple sclerosis [29].

\section{PREVENTION OF RELAPSES DURING THE POSTPARTUM PERIOD}

As Dutch philosopher Erasmus stated that "prevention is better than cure", strategies were nominated in order to address the significant risk of relapse during the postpartum months, acknowledging the particular features of this period. Treatment for prevention of relapses include corticosteroids, immunoglobulins or hormonal therapy, among others. In opposition to the use of intravenous immunoglobulins for the prevention of relapse that needs to be further investigated, in a 2004 study conducted by de Seze, during the postpartum period, women diagnosed with multiple sclerosis who were monthly administered $1 \mathrm{~g}$ of intravenous corticosteroids for 6 months, experienced a smaller relapse rate [30]. Moreover, in 2011, Ornelas used a retrospective study in which a single dose of $1 \mathrm{~g}$ of intravenous methylprednisolone was given in the postpartum period, the conclusions of the study reiterating its statistically significant benefit on the relapse rate [31]. Furthermore, multiple studies have addressed the issue of using hormonal therapy in order to prevent multiple sclerosis relapses during the postpartum period. Vukusic et al. conducted an European, multicenter, randomized, placebo-controlled and double-blind clinical trial, with the goal to prevent multiple sclerosis relapses in the postpartum period, using progestin and endometrial protective doses of estradiol and it was hypothesized that sexual steroids could bring favorable outcomes by influencing the immune circumstances, diminishing the pro-inflammatory lymphocyte responses of the Th1 type and augmenting the anti-inflammatory responses of the Th2 type [32]. An additional role could be observed in remyelination of central nervous system lesions and peripheral nervous system, while progesterone might influence myelin sheath formation after a cryolesion of the male mouse sciatic nerve [32]. However, the results of the study above-mentioned were not conclusive.

\section{TREATMENT OF PREGNANT WOMEN WITH MULTIPLE SCLEROSIS}

As multiple sclerosis affects women 2.5 times more frequent than men and it is usually diagnosed between 20 and 40 years of age, current recommendations persuade women pertaining to the reproductive age group to plan a pregnancy during the low activity period of the disease, with available disease modifying therapies (DMTs) as treatment options. First-line therapies include Interferons $\beta$, Glatiramer acetate, Teriflunomide and Dimethylfumarate, while second-line therapies include Fingolimod, Natalizumab, Mitoxantrone, Alemtuzumab, Ocrelizumab and Cladribine, with the remark that recent European guidelines on multiple sclerosis pharmacological management precisely illustrate that any category of treatment should be interrupted during pregnancy, while further study should be implemented for the pregnancy and postpartum period [33].

Hellwig et al. retrieved pregnancy cases with exposure to interferon beta-1b from January 1995 to February 2018, concluding that there was no increase in the rate of abnormal pregnancy outcomes and the percentage of spontaneous abortion and major or minor birth defects was not higher compared to the general population [34]. Currently, Interferons $\beta$ are used until conception, with further investigation being needed for pregnancy and postpartum period. Glatiramer acetate is another first-line therapy that can be used until conception, with the need of further analysis for the parturiency time. There is a shortage of studies that have evaluated the safety of in utero exposure to glatiramer acetate, the study conducted by Giannini et al. being one of them. The 2012 study concluded that the risk of spontaneous abortion and other outcomes did not increase after glatiramer acetat exposure and the miscarriage rate $(17 \%)$ is similar to the one in the general population [35]. Teriflunomide is a single-daily dose of oral immunomodulator used for multiple sclerosis treatment, contraindicated in pregnant women or in women planning a potential pregnancy, considering the potential risk of teratogenicity and embryo-lethality, and when pregnancy is confirmed, women undergoing teriflunomide are recommended accelerated elimination procedure until plasma concentrations reach under $0.02 \mathrm{mg} / \mathrm{l}$, a rate that could involve the lowest risk to the fetus [36]. Dimethylfumarate is another oral agent used as a first-line therapy for multiple sclerosis treatment, pregnant women mostly being excluded from targeted trials. However, Gold et al., in a 2015 paper, reported that out of 4,132 subjects from which 2,898 patients were diagnosed with multiple sclerosis, 
results have shown that the risk of fetal abnormalities or adverse pregnancy outcomes associated with gestational exposure was inconsequential [37].

One of the second-line therapy medications, fingolimod is contraindicated in pregnancy, contraception being recommended for 2 months before conception. Leon et al. reported that by 28th February 2019, 1586 prospective cases of maternal fingolimod exposure during pregnancy were analyzed, the prevalence of major congenital malformations among live births being between 2.04 and $5.3 \%$, without discernible pattern of specific malformation [38]. Natalizumab is a monoclonal antibody which exerts its action on $\alpha 4 \beta 1$ integrin, with recommendation of cessation during pregnancy, especially in the third trimester when the risk of fetal hematological anomalies is high [39]. Ocrelizumab and Cladribine maintain the recommendation of contraception during treatment and a few months after cessation [39]. Few studies have addressed the issue of maternal exposure to mitroxantone during pregnancy, Hellwig et al. noting that in one case of maternal exposure, the neonate was diagnosed with Pierre Robin sequence that included glossoptosis, micrognathia and palate clefts, hence being considered a potential teratogen and being contraindicated during pregnancy [40]. In the most recent article published on 15th April 2021 on alemtuzumab and pregnant women diagnosed with multiple sclerosis, Russo et al. reported that out of seven women, five live births successfully happened without congenital outcomes or birth defects [41].

\section{CONCLUSIONS}

In recent years, the percentage of women diagnosed with multiple sclerosis and obtaining a pregnancy has increased, thus emphasizing the essential role of a multidisciplinary team that involves obstetricians, neurologists and anesthesiologists. Although multiple sclerosis benefits from a wide range of disease modifying therapies (DMTs) as treatment options, the majority of these therapies are contraindicated during pregnancy or in the early postpartum period. Understanding the factors that determine multiple sclerosis is essential in providing a proper care, especially during pregnancy. Nonetheless, health care providers should be informed that they could access the online database that it used as a reference center for teratogen agents. Further studies are needed to be implemented in order to find available therapies for the pregnancy or postpartum period.

\section{Acknowledgement \\ All authors equally contributed to this article.}

Conflict of interest: none declared Financial support: none declared

\section{REFERENCES}

1. Confavreux $\mathrm{C}$, Hutchinson $\mathrm{M}$, Hours MM, CortinovisTourniaire P, Moreau T. Rate of pregnancy-related relaps in multiple sclerosis. Pregnancy in Multiple Sclerosis Group. N Engl J Med 1998;339:285-91.

2. Compston A, Coles A. Multiple sclerosis. Lancet. 2008 Oct 25;372(9648):1502-17.

3. Weiner HL. A shift from adaptive to innate immunity: a potential mechanism of disease progression in multiple sclerosis. J Neurol. 2008 Mar;255 Suppl 1:3-11.

4. Khan F, Turner-Stokes L, Ng L, Kilpatrick T. Multidisciplinary rehabilitation for adults with multiple sclerosis. J Neurol Neurosurg Psychiatry. 2008 Feb;79(2):114.

5. Boiko A, Vorobeychik G, Paty D, Devonshire $\mathrm{V}$, Sadovnick D; University of British Columbia MS Clinic Neurologists. Early onset multiple sclerosis: a longitudinal study. Neurology. 2002 Oct 8;59(7):1006-10.

6. Gandhi R, Laroni A, Weiner HL. Role of the innate immune system in the pathogenesis of multiple sclerosis. J Neuroimmunol. 2010 Apr 15;221(1-2):7-14.

7. Zhu J, Paul WE. CD4 T cells: fates, functions, and faults. Blood. $2008 \mathrm{Sep}$ 1;112(5):1557-69.

8. Fujinami RS, von Herrath MG, Christen U, Whitton JL. Molecular mimicry, bystander activation, or viral persistence: infections and autoimmune disease. Clin Microbiol Rev. 2006 Jan;19(1):80-94.

9. Dawson VL, Dawson TM, Bartley DA, Uhl GR, Snyder SH. Mechanisms of nitric oxide-mediated neurotoxicity in primary brain cultures. J Neurosci. 1993 Jun;13(6):2651-61.

10. Merrill JE, Ignarro LJ, Sherman MP, Melinek J, Lane TE. Microglial cell cytotoxicity of oligodendrocytes is mediated through nitric oxide. J Immunol. 1993 Aug 15; 151(4):2132-41.

11. Mitrovic B, Ignarro LJ, Vinters HV, Akers MA, Schmid I, Uittenbogaart $C$, et al. Nitric oxide induces necrotic but not apoptotic cell death in oligodendrocytes. Neuroscience. 1995;65(2):531-539.

12. VanAmerongen BM, Dijkstra CD, Lips $P$, Polman $\mathrm{CH}$. Multiple sclerosis and vitamin D: an update. Eur J Clin Nutr. 2004;58(8):1095-1109.

13. Chen S, Sims GP, Chen XX, Gu YY, Chen S, Lipsky PE. Modulatory effects of 1,25-dihydroxyvitamin D3 on human B Cell differentiation. J Immunol. 2007; 179(3):1634-1647.

14. Mowry EM, Krupp LB, Milazzo M, Chabas D, Strober JB, Belman AL, et al. Vitamin D status is associated with relapse rate in pediatric-onset multiple sclerosis. Ann Neurol. 2010;67(5):618-624.

15. Banwell B, Bar-Or A, Arnold DL, Sadovnick D, Narayanan S, McGowan M, et al. Clinical, environmental, and genetic determinants of multiple sclerosis in children with acute demyelination: a prospective national cohort study. Lancet Neurol. 2011;10(5):436-445.

16. Disanto G, Morahan JM, Ramagopalan SV. Multiple sclerosis: risk factors and their interactions. CNS Neurol Disord Drug Targets. 2012;11(5):545-555.

17. Wade DT, Young CA, Chaudhuri KR, Davidson DL. A randomised placebo controlled exploratory study of vitamin B-12, lofepramine, and L-phenylalanine (the "Cari Loder regime") in the treatment of multiple sclerosis. J Neurol Neurosurg Psychiatry. 2002 Sep;73(3):246-9.

18. Sloka S, Silva C, Pryse-Phillips W, Patten S, Metz L, Yong VW. A quantitative analysis of suspected environmental causes of MS. Can J Neurol Sci. 2011 Jan;38(1):98-105.

19. Ebers GC, Sadovnick AD, Risch NJ. A genetic basis for familial aggregation in multiple sclerosis. Canadian Collaborative Study Group. Nature. 1995 Sep 14;377(6545):150-1. 
20. Wolinsky, J.S. Multiple sclerosis. Curr Neurol. 1989;13:167.

21. Dahl J, Myhr KM, Daltveit AK, et al. Pregnancy, delivery and birth outcome in different stages of maternal multiple sclerosis. J Neurol. 2008;255:623-627.

22. van der Kop ML, Pearce MS, Dahlgren L, Synnes A, Sadovnick D, Sayao AL, Tremlett $\mathrm{H}$. Neonatal and delivery outcomes in women with multiple sclerosis. Ann Neurol. $2011 \mathrm{Jul} ; 70(1): 41-50$.

23. Pastò L, Portaccio E, Ghezzi A, Hakiki B, Giannini M, Razzolini L, Piscolla E, et al.; MS Study Group of the Italian Neurological Society. Epidural analgesia and cesarean delivery in multiple sclerosis post-partum relapses: the Italian cohort study. BMC Neurol. 2012 Dec 31;12:165.

24. Ray JG, Vermeulen MJ, Bharatha A, Montanera WJ, Park AL. Association Between MRI Exposure During Pregnancy and Fetal and Childhood Outcomes. JAMA. 2016;316(9):952-961.

25. Paavilainen T, Kurki T, Parkkola R, Färkkilä M, Salonen O, Dastidar P, Elovaara I, Airas L. Magnetic resonance imaging of the brain used to detect early post-partum activation of multiple sclerosis. Eur J Neurol. 2007 Nov;14(11):1216-21.

26. Drake E, Drake M, Bird J, Russell R. Obstetric regional blocks for women with multiple sclerosis: a survey of UK experience. Int J Obstet Anesth. 2006 Apr;15(2):115-23.

27. Lavie C, Rollot F, Durand-Dubief F, et al. Neuraxial analgesia is not associated with an increased risk of post-partum relapses in MS. Multiple Sclerosis Journal. 2019;25(4):591-600.

28. Langer-Gould A, Huang SM, Gupta R, Leimpeter AD, Greenwood E, Albers KB, Van Den Eeden SK, Nelson LM. Exclusive breastfeeding and the risk of postpartum relapses in women with multiple sclerosis. Arch Neurol. 2009 Aug;66(8):958-63.

29. Zuluaga MI, Otero-Romero S, Rovira A, Perez-Hoyos S, Arrambide G, Negrotto L, et al. Menarche, pregnancies, and breastfeeding do not modify long-term prognosis in multiple sclerosis. Neurology. 2019 Mar 26;92(13):e1507-e1516.

30. de Seze J, Chapelotte M, Delalande S, Ferriby D, Stojkovic T, Vermersch P. Intravenous corticosteroids in the postpartum period for reduction of acute exacerbations in multiple sclerosis. Mult Scler. 2004 Oct;10(5):596-7.

31. Avila-Ornelas J, Avila M, Stosic M, et al. The role of postpartum intravenous corticosteroids in the prevention of relapses in multiple sclerosis. Int J MS Care. 2011;13(2):91-93

32. Vukusic S, Ionescu I, El-Etr M, Schumacher M, Baulieu EE, Cornu C, Confavreux C. Prevention of Post-Partum Relapses with Progestin and Estradiol in Multiple Sclerosis Study Group. The Prevention of Post-Partum Relapses with Progestin and Estradiol in Multiple Sclerosis (POPART'MUS) trial: rationale, objectives and state of advancement. J Neurol Sci. 2009 Nov 15;286(1-2):114-8

33. Montalban X, Gold R, Thompson AJ, Otero-Romero S, Amato MP, Chandraratna D, et al. ECTRIMS/EAN Guideline on the pharmacological treatment of people with multiple sclerosis. Mult Scler. 2018; 24:96-120

34. Hellwig K, Duarte Caron F, Wicklein EM, Bhatti A, Adamo A. Pregnancy outcomes from the global pharmacovigilance database on interferon beta- $1 \mathrm{~b}$ exposure. Ther Adv Neurol Disord. 2020;13:1756286420910310.

35. Giannini M, Portaccio E, Ghezzi A, et al. Pregnancy and fetal outcomes after Glatiramer Acetate exposure in patients with multiple sclerosis: a prospective observational multicentric study. BMC Neurol. 2012;12:124.

36. Kieseier BC, Benamor M. Pregnancy outcomes following maternal and paternal exposure to teriflunomide during treatment for relapsing-remitting multiple sclerosis. Neurol Ther. 2014;3(2):133-138.

37. Gold R, Phillips JT, Havrdova E, Bar-Or A, Kappos L, Kim N, Thullen T, Valencia P, Oliva L, Novas M, Li J, Sweetser MT, Kurukulasuriya N, Viglietta V, Fox RJ. Delayed-Release Dimethyl Fumarate and Pregnancy: Preclinical Studies and Pregnancy Outcomes from Clinical Trials and Postmarketing Experience. Neurol Ther. 2015 Dec;4(2):93-104.

38. Hellwig K. Effect of fingolimod on pregnancy outcomes in patients with multiple sclerosis. Available at: https://onlinelibrary.ectrimscongress.eu/ectrims/2019/ stockholm/278772/kerstin. hellwig.effect.of. fingolimod.on.pregnancy.outcomes.in. patients.with. ?f=listing $\% 3 \mathrm{D} 3 \% 2$ Abrowseby\%3D8\%2Asortby \%3D2\%2Amedia\%3D3\% 2Asearch\%3 Dpregnancy (accessed April 18, 2021).

39. Vukusic S, Michel L, Leguy S, Lebrun-Frenay C. Pregnancy with multiple sclerosis. Rev Neurol (Paris). 2021 Mar;177(3):180-194.

40. Hellwig K, Schimrigk S, Chan A, Epplen J, Gold R. A newborn with Pierre Robin sequence after preconceptional mitoxantrone exposure of a female with multiple sclerosis. J Neurol Sci. 2011 Aug 15;307(1-2):164-5.

41. Russo CV, Lanzillo R, Saccà F, Moccia M, Carotenuto A, Brescia Morra V. Pregnancy outcomes in alemtuzumab treated women with multiple sclerosis: a case series. Neurol Sci. 2021 Apr 15. 